residing within the Association's boundaries but do not yet have three years in practice may also apply for Candidate membership.

An application must include the following uploads: a photo; a complete curriculum vitae with bibliography; and, for Active applicants, the 3 most significant articles that s/he personally wrote. The application must be completed and submitted online by March 1, 2016, and all support letter(s) (three for Active applicants, one for Candidates) uploaded by that applicant's sponsor(s) by March 31, 2016, in order for the applicant to be considered for election to membership at the 2016 Annual Meeting.

\section{WTSA 42nd Annual Meeting}

\section{Save the Date!}

June 22-25, 2016

Hilton Waikoloa Village

Waikoloa, Hawaii

\section{The American Board of Thoracic Surgery}

\section{ABTS Announcement}

The American Board of Thoracic Surgery's Maintenance of Certification program was adopted 7 years ago. Since that time, there has been a continuous evaluation in the Board's thinking about the overall process, based upon internal discussions and input from our diplomates.

These inputs resulted in our decision to migrate from a purely knowledge-based multiple-choice exam, using a Pearson Testing Center, to a Mastery Learning Process, using a SESATS format. Diplomates, enrolled in this year's (2015) 10-year MOC process, will fulfill their Part III requirement by completion of a home or office-based secure learning exam, following the instructions on the ABTS Web site.

In brief, you will be directed to a secure Web site, administered by Software Secure. The only special computer hardware needed will be a camera for your home or office computer (most laptops now come with a built-in camera). Once logged in, you will be asked to verify your identity by holding up your driver's license with your picture next to your face. You will be visually monitored for the time you are logged onto the Web site.

There are 100 SESATS questions (primarily taken from SESATS X), based on your specialty designation (Adult Cardiac, General Thoracic, Cardiothoracic, and Congenital), that you will need to work through as instructed. The exam will now be modular and tailored to your practice-for example, if your practice is $100 \%$ adult cardiac, you will only have adult cardiac and critical care questions. You will have 15 hours with as many as 10 logins to complete the 100 questions during the months of September and October 2015. For those diplomates who have used SESATS in the past, the process of working through the questions is the same. For those who aren't familiar with SESATS, it might be beneficial to purchase and download SESATS X and work through the specialty-specific module.
This preparation will give you familiarity with the process. While SESATS X may be helpful preparation, it is not required.

The goal of this exam is to provide a learning opportunity using judgement and decision making as well as knowledge. There is no grade involved, but you will be given the percentage of questions you answered correctly on the first try.

Not passing this exam would result from either not completing the 100 questions in the 15 -hour and 10-login limit or by rushing through the questions without reading the critique. The Board and MOC Committee believe that reading the critique is key to the learning process using SESATS. The Software Secure reporting system will allow us to verify the pace of completion and thus limit the passing grades to those who earnestly participate in the process.

The Board sincerely hopes that this pilot of life-long learning is viewed favorably by our diplomates. If the diplomates find this form of learning better than the previous approach that used a secured multiple-choice test administered in a remote testing center, the Board will continue with this new strategy and refine SESATS as we go forward to assure that new standards of care are communicated to members of the ABTS community as part of the MOC process. There will be a brief survey following the last SESATS question, which needs to be completed to officially finish the process.

Everyone at the ABTS thanks you for embracing the primary principle of MOC-life-long learning, which is consistent with our obligation to the public trust.

\section{ABTS Requirements for the 10-Year Milestone for Maintenance of Certification}

Diplomates of the American Board of Thoracic Surgery (ABTS) who plan to participate in the 10-Year Milestone for the Maintenance of Certification (MOC) process as Certified-Active must hold a currently valid, full, and unrestricted license to practice medicine. Diplomates must provide delineation of privileges at a hospital(s) accredited 
by the JCAHO or other institutions judged acceptable by the Board. Diplomates must also submit letter(s) of reference documenting their level of clinical activity and stature within the surgical community from the VP of Medical Affairs and one other responsible member on staff at their principal hospital. In addition, a valid ABTS certificate is an absolute requirement for entrance into the MOC process. If your certificate has expired, the only pathway for renewal of a certificate is to take and pass the Part I (written) and the Part II (oral) certifying examinations.

The CME requirements are 150 Category I credits over a five-year period. At least half of these CME hours need to be in the broad area of thoracic surgery. Category II credits are not accepted. Interested individuals should refer to the Board's Web site (www.abts.org) for a complete description of acceptable CME credits.

This year, the Board has changed the format of the MOC exam. Instead of taking the MOC exam at a testing center, the Board wants Diplomates to be aware that they will be taking the exam on their personal or office computer. The Diplomate will need to have a Web camera that will work in conjunction with the software for security purposes. The Board is transitioning to using SESATS as the mastery learning tool. Each time a Diplomate logs on to the site, he or she will be asked to hold his or her license (with a picture) to secure verification. The Diplomate will also be asked to provide a scan of the immediate area for security purposes.

The online MOC exam must be completed during the time period of September 1, 2015, to October 31, 2015. Diplomates will be allowed to enter the online program 10 times for a total of 15 hours. If the exam is not completed within those parameters, it will be considered incomplete. The fee for sitting for the MOC secure exam is $\$ 125.00$. This fee covers the expenses associated with software needed to ensure the online exam is secure. Questions on the MOC exam will be modular, based on your specialty, and presented in a self-assessment format.

The American Board of Thoracic Surgery has voted to replace the requirement for mandatory database participation with Performance Improvement. The Board is requiring clinically active Diplomates to participate in a Practice Quality Improvement (PQI) project by January 2016. For those clinically active Diplomates who do not participate in a Board-approved database/ registry, the Board will continue to require participation in the Professional Portfolio until the PQI process starts.

Diplomates may apply for MOC in the year their certificate expires or, if they wish to do so, they may apply up to two years before it expires. However, the new certificate will be dated 10 years from the date of expiration of their original certificate or most recent MOC certificate. In other words, going through the MOC process early does not alter the 10-year validation. Diplomates certified prior to 1976 (the year that time-limited certificates were initiated) are also required to participate in MOC if they wish to maintain valid certificates.

Information outlining the rules, requirements, and application deadline for the 10-year Milestone of MOC in thoracic surgery is available on the Board's Web site at www. abts.org. For additional information, please contact the American Board of Thoracic Surgery, 633 N Saint Clair St, Ste 2320, Chicago, IL 60611; telephone (312) 2025900; fax (312) 202-5960; E-mail: sesats@abts.org.

\section{Thoracic Surgery Foundation for Research and Education}

\section{TSFRE 2016 Awards Program}

Thoracic Surgery Foundation for Research and Education (TSFRE) is offering several 2016 awards to qualified applicants. Please visit the TSFRE Awards Page or www.tsfre.org for detailed information and to access grant applications. Questions about eligibility can be directed to Priscilla Kennedy, TSFRE Executive Director, by E-mail at pkennedy@tsfre.org. The application deadline for the following awards is October 15, 2015.

\section{TSFRE Research Grant}

Provides operational support for original research efforts by cardiothoracic surgeons who have completed their formal training, and who are seeking initial support and recognition for their research program. Awards of up to $\$ 40,000$ per year for up to two years are granted to support the work of an early-career cardiothoracic surgeon (within five years of first faculty appointment at time of application deadline).

\section{Acelity Wound Care Research Grant}

TSFRE, through the generosity and philanthropy of Acelity, is offering support of up to $\$ 25,000$ to support the research efforts by cardiothoracic surgeons who have completed their formal training, and who are seeking support and recognition for their research program related to wound care management. This is the first year this award is being offered, and is focused on wound healing, care, and infection improvement.

\section{TSFRE/Edwards Lifesciences Every Heartbeat Matters} Award

TSFRE, through the generosity and philanthropy of the Edwards Lifesciences Foundation via its Every Heartbeat 